\title{
Diagnóstico del carcinoma escamoso de la mucosa bucal: reporte de 5 casos
}

\author{
Baudo JE
}

\section{RESUMEN}

Es indudable que el cáncer bucal causa un importante número de muertes a nivel mundial. El cáncer invasivo puede permanecer largo tiempo bajo cambios macroscópicos inespecíficos, sólo la biopsia permite su diagnóstico. La técnica más utilizada es la rutina con hematoxilina - eosina, actualmente se agrega a la misma otras que contribuyen a clarificar el diagnóstico, por ejemplo la inmunohistoquímica, que en muchos casos determinará la estirpe de una neoplasia.

Palabras claves: Carcinoma escamoso - Diagnóstico - Histopatología - Inmunohistoquímica - Oncoproteínas.

\section{SUMMARY}

It is certain that the cancer buccal cause an important number of deaths at world level. The cancer invasivo can remain long time low changes macroscopic unspecific, the biopsy only allows its diagnosis. The more used technique is the routine with hematoxylin - eosin, at the moment is added to the same others that contribute to clarify the diagnosis, for example the inmunohistoquímica that will determine the stock of a neoplasia in many cases.

Key words: Squamous Carcinoma - Diagnosis - Histopathology - Inmunohistochemistry - Oncoproteins.

Aceptado para publicación: Septiembre 2004.

* Jefe de Trabajos Prácticos de la Asignatura de Patología y Clínica. Estomatológica de la Facultad de Odontología de la UNLP

Baudo JE. Diagnóstico del carcinoma escamoso de la mucosa bucal: reporte de 5 casos. Av. Odontoestomatol 2005; 21-4: 203-209.

\section{INTRODUCCIÓN}

El tratamiento oncológico depende en gran medida del diagnóstico histológico. Esto es fácil en tumores externos, pero más complicado en neoplasias internas, si bien la ecografía y la TAC, así como otras técnicas combinadas con la punción biopsia y la citología aspirativa, han permitido mejorar la situación previa. La inmunohistoquímica ha facilitado notablemente la identificación de productos celulares o de marcadores superficiales.

Histológicamente este tumor presenta células neo- plásicas proliferantes con atipías celulares y un estroma de soporte. Los trastornos intracelulares pueden originar defectos en los desmosomas o reducir su número de manera que se reciente la adherencia celular y se altera la distribución de tonofibrillas. En ocasiones se originan desmosomas intracitoplasmáticos, así como cuerpos lisosómicos, éstos últimos favorecen la invasividad del carcinoma bucal porque producen colagenasas.

La técnica de inmunofluorescencia fue modificada con la introducción de una técnica con inmunoenzimas en 1966, año en el que Nakane y Pierce (1), uti- 
lizaron con éxito la perioxidasa de rábano, iniciando la era de la inmunohistoquímica enzimática. El método que utilizaron fue descripto poco antes por Graham y Karnovsky (2), consiste en hacer reaccionar la peroxidasa con su sustrato específico, el peróxido de hidrógeno, en presencia del cromógeno. La técnica de inmunoperoxidasa ofrece múltiples ventajas frente a la inmunofluorescencia, entre éstas: aumento de la sensibilidad, poder utilizar tejidos congelados, fijados en formol y secciones en parafina, capacidad para ser contrastada con tinciones de rutina (hematoxilina) y posibilidad de doble tinción en la misma sección tisular. (3-4)

El objetivo de este trabajo es presentar un estudio histopatológico e inmunohistoquímico de 5 casos de carcinoma escamoso de la mucosa bucal a fin de registrar las características más relevantes.

\section{MATERIAL Y MÉTODO}

$\checkmark$ Se seleccionó aleatoriamente 5 piezas quirúrgicas de carcinoma escamoso de la mucosa bucal.

$\checkmark$ Se practicaron secciones tisulares para tinción con hematoxilina-eosina.

$\checkmark$ A los cortes se les eliminó la parafina y se los hidrató. Como disolvente de la parafina se utilizó el xilol, posteriormente se los pasó por los alcoholes, comenzando por los de mayor gradación y terminando por el agua para su hidratación. Posteriormente se dio comienzo a la coloración con hematoxilina y viraje de la misma con agua corriente, para pasar luego a la eosina. Los tiempos en que actuaron cada una de estas sustancias sería:

1. Xilol, 8 minutos.

2. Alcohol a $100^{\circ}$, arrastre de xilol.

3. Alcohol a $90^{\circ}$, arrastre de alcohol $100^{\circ}$.

4. Alcohol a $70^{\circ}$, arrastre de alcohol $90^{\circ}$.

5. Agua, arrastre de alcohol $70^{\circ}$.

6. Hemalumbre ácido de Mayer, 10 minutos o más. Agua corriente (viraje), 5 minutos o más.

7. Eosina (solución alcohólica), medio minuto. Deshidratación, aclaración. (5)

$\checkmark$ Se clasificó según los grados de diferenciación de la OMS. En muchos preparados se encontraron más de un grado de diferenciación.

Se obtuvieron cortes para técnicas de inmunomarcación para la detección de P53, Mib-1 y cerB-2.

En cuanto a la biología celular de estos tumores, los genes supresores son los que han recibido mayor atención y dentro de ellos, el P-53 se ha visto alterado con mayor frecuencia en los carcinomas del tracto aerodigestivos superior.

La sobreexpresión o mutación de P-53, se ha demostrado con mayor frecuencia en células de carcinoma de la mucosa oral, que en cualquier otro cáncer humano, por lo que evaluamos en 5 carcinomas escamosos de dicha mucosa.

En cuanto a la actividad proliferativa tumoral que refleja su potencial biológico y puede evaluarse por distintos métodos, hemos también utilizado técnicas de inmunomarcación para la demostración de un marcador de proliferación tumoral, Ki-67 (clon Mib1 Novocastra) de localización nuclear, con tinción específica a este nivel.

En lo que se refiere a oncoproteínas, evaluamos la presencia o no de c-erB-2, en estos 5 tumores, con el mismo procedimiento utilizado para P-53 y Mib-1. Este protooncogen, codifica una proteína de membrana que es detectable por inmunomarcación y se consideró positiva solamente en aquellos casos con clara tinción de la membrana celular.

\section{Procedimiento técnico empleado}

Se utilizaron cortes en blanco, de tacos parafinados, provenientes de tejidos fijados en formol. Después de la desparafinización, se realizó inhibición de la peroxidasa endógena con Metanol y agua oxigenada por 30 minutos. Posteriormente, realizamos desenmascaramiento antigénico con Buffer Citrato, en Microondas durante 15 minutos, después de lo cual los cortes se incubaron durante 20 minutos en suero normal de caballo.

El paso siguiente consistió en la colocación del anti- 
cuerpo primario (en nuestro caso P-53, Mib-1 y cerB-2), con incubación overnight. Luego incubamos con una solución de anticuerpo secundario biotinilado (1:100) por 30 minutos y posteriormente con una solución de Avidina-peroxidasa (1:80) (Vectastain $A B C)$, por 30 minutos también.

Finalmente, para el revelado, utilizamos una solución con Diaminobencidina por 5 minutos y contraste con Hematoxilina.

\section{RESULTADOS}

\section{Histológicos (Tabla 1)}

Surgen como características histopatológicas más relevantes: queratinización bajo formas de globos córneos, hipercromasia, polimorfismo nuclear y celular, mitosis y presencia de infiltrado inflamatorio crónico inespecífico. (Figuras 1, 2 y 3)

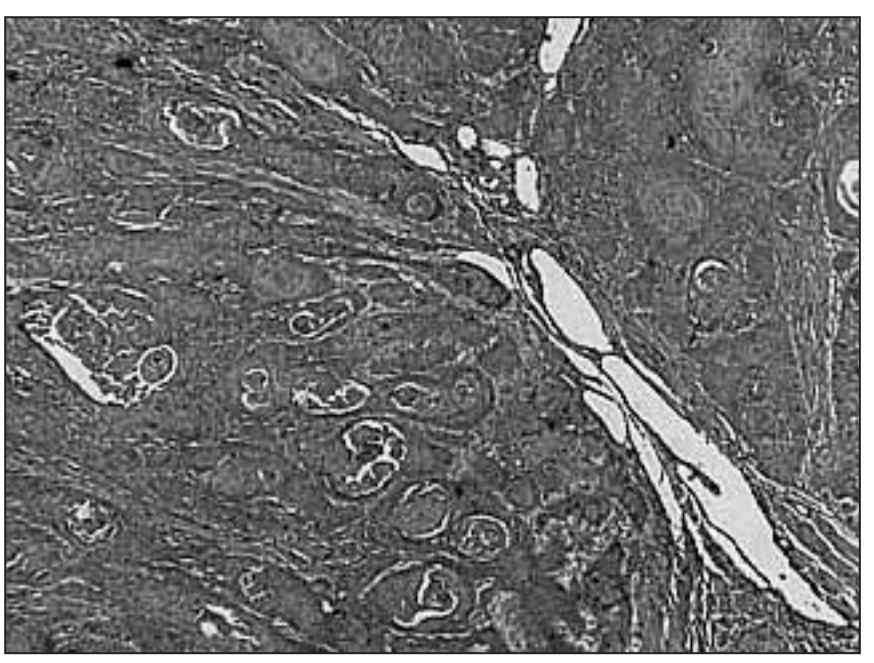

Fig. 1. x 2,5 de aumento. Abundantes glóbulos córneos.

\begin{tabular}{|l|c|l|l|l|}
\hline \multicolumn{5}{|c|}{ TABLA 1.- RESULTADOS HISTOPATOLÓGICO } \\
\hline Caso & $\begin{array}{l}\text { Grado } \\
\text { diferenciación }\end{array}$ & Aumento X 2,5 & \multicolumn{1}{c|}{ Aumento X 10 } & \multicolumn{1}{c|}{ Aumento $X$ 40 } \\
\hline 1 - Mucosa yugal & I y II & $\begin{array}{l}\text { Masas epiteliales. } \\
\text { Abundante } \\
\text { infiltrado. }\end{array}$ & $\begin{array}{l}\text { Atipías celulares. } \\
\text { Hipercromasia. } \\
\text { Abundante infiltrado. }\end{array}$ & $\begin{array}{l}\text { Pérdida de la adhesión } \\
\text { celular. Polimorfismo } \\
\text { nuclear. Leve } \\
\text { disqueratosis. }\end{array}$ \\
\hline 2 - Labio & II & $\begin{array}{l}\text { Infiltración en } \\
\text { cordones. }\end{array}$ & $\begin{array}{l}\text { Disqueratosis y } \\
\text { abundantes globos } \\
\text { córneos. }\end{array}$ & $\begin{array}{l}\text { Pérdida de la adhesión } \\
\text { celular. Polimorfismo } \\
\text { nuclear y celular. } \\
\text { Disqueratosis. }\end{array}$ \\
\hline 3 - Lengua & I & $\begin{array}{l}\text { Digitaciones } \\
\text { invadiendo el } \\
\text { corion. } \\
\text { Disqueratosis. }\end{array}$ & $\begin{array}{l}\text { Hiperplasia escamosa. } \\
\text { Disqueratosis. } \\
\text { Imágenes compatibles } \\
\text { con coilocitosis. } \\
\text { Infiltrado inespećfico. }\end{array}$ & $\begin{array}{l}\text { Pérdida de la adhesión } \\
\text { celular. Polimorfismo } \\
\text { celular. Hipercromasia. } \\
\text { Pérdida de polarización. } \\
\text { Cédulas binucleadas. } \\
\text { Mitosis. }\end{array}$ \\
\hline 4 - Encía & I y II & $\begin{array}{l}\text { Abundante invasión } \\
\text { del estroma. } \\
\text { Disqueratosis. }\end{array}$ & $\begin{array}{l}\text { Abundante } \\
\text { disqueratosis. } \\
\text { Abundante infiltrado. }\end{array}$ & $\begin{array}{l}\text { Abundante disqueratosis. } \\
\text { Pérdida de la acción } \\
\text { celular,. Polimorfismo } \\
\text { nuclear. Hipercromasia }\end{array}$ \\
\hline 5 - Lengua y piso \\
de boca
\end{tabular}




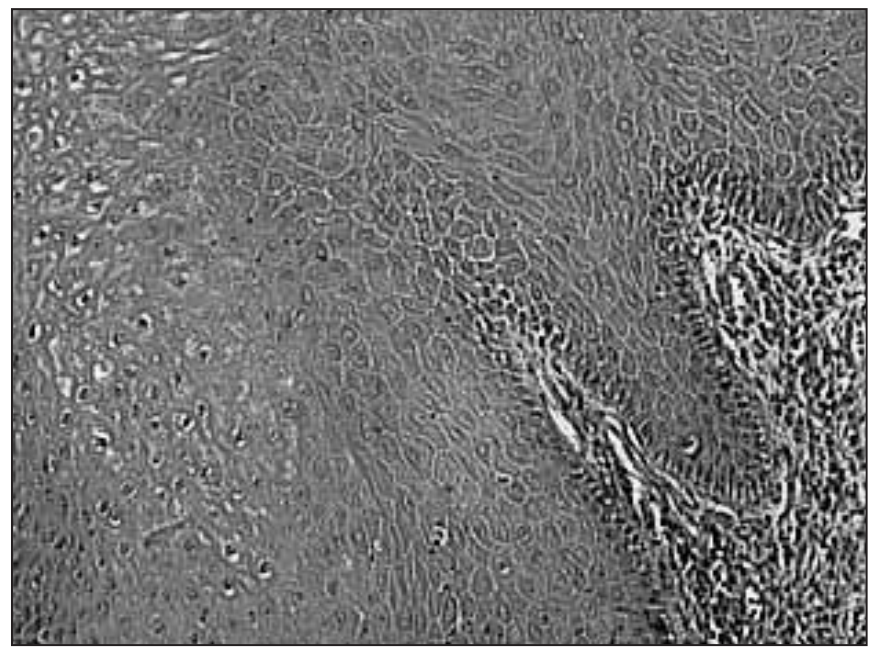

Fig. 2. x 10 de aumento. Prolongaciones digitiformes tumorales. Avanzando en el estroma con reacción linfocitaria.

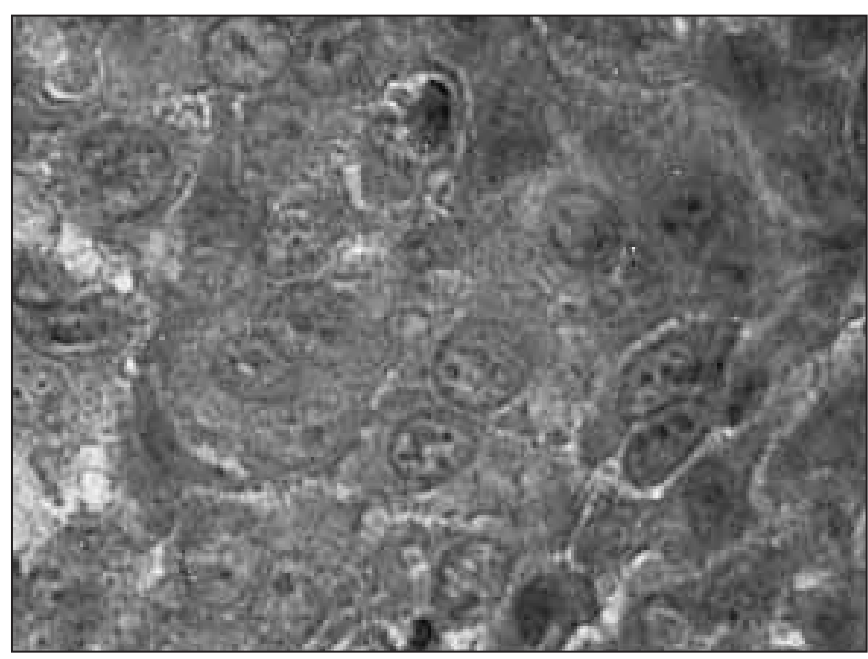

Fig. 3. x 40 de aumento. Disqueratosis. Perla córnea, hipercromasia. Pleomorfismo, pérdida de adhesión celular.

\section{Inmunohistoquímicos}

La sobreexpresión de la proteína P53 está relacionada con la prognosis, en los 5 especímenes marcados, hubo positividad con el inmunosuero específico para dicha proteína y con el inmunosuero para la proteína Mib-1. (Figuras 4 y 5).

\section{DISCUSIÓN}

Las características histopatológicas más importantes que surgieron del estudio de los 5 casos seleccionados son parámetros observados por la mayoría de los autores. (6)

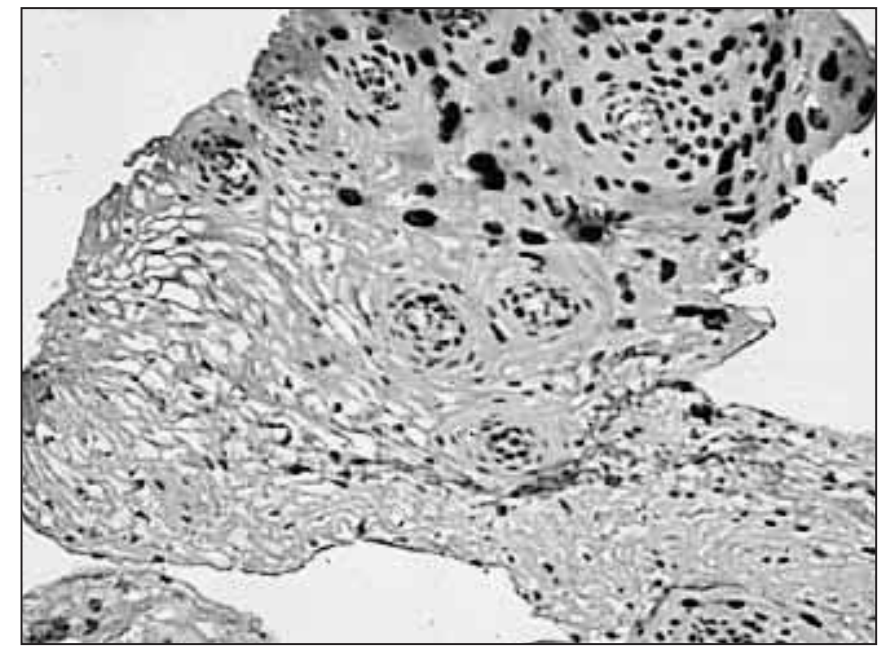

Fig. 4. Marcación positiva para Mib-1.

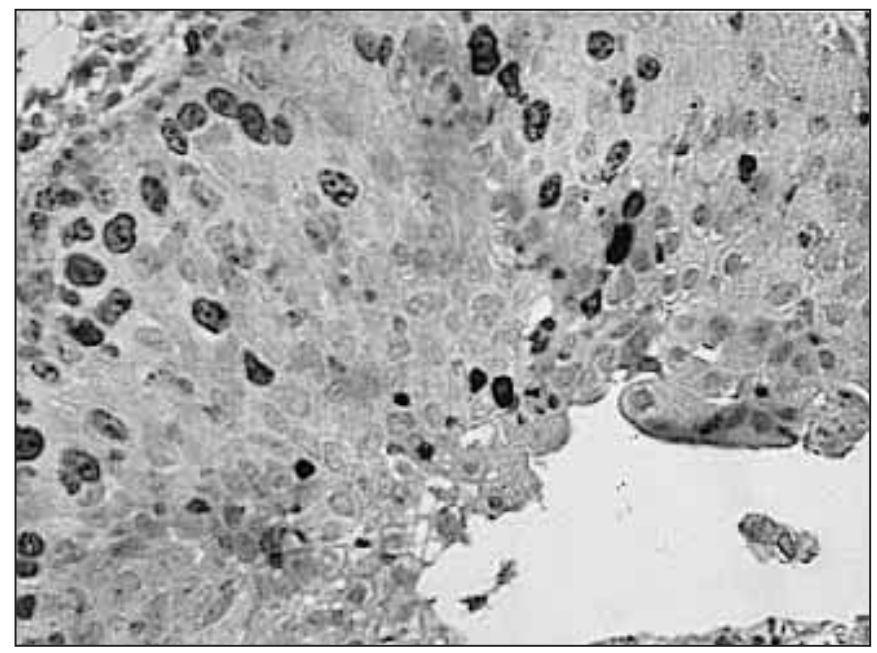

Fig. 5. Marcación positiva para P53.

Los resultados inmunohistoquímicos, en muchos casos, determinarán la estirpe de una neoplasia y conducirá a un diagnóstico preciso. Por este motivo, es preciso recordar que las técnicas inmunohistoquímicas, a pesar del gran avance que han experimentado en los últimos años, siguen adoleciendo de variabilidad y problemas de sensibilidad y/o especificidad, en mayor o menor grado, dependiendo del anticuerpo utilizado, de las características de los tejidos, del procedimiento inmunohistoquímico y de la pericia del personal encargado de realizarlas.

Procesamiento de los tejidos: La congelación de los tejidos no fijados constituye la mejor forma de conservar la antigenicidad, sin embargo plantea dificultades añadidas a la inclusión rutinaria de los tejidos en parafina. Los estudios retrospectivos no permiten el 
uso de anticuerpos únicamente aplicables a tejidos congelados, ya que los tejidos almacenados en casi todos los laboratorios están incluidos en parafina.

Las variaciones de $\mathrm{pH}$, tiempo de fijación, temperatura y características de la fijación, influirán sobre la antigenicidad de la muestra estudiada. (7-8)

Los medios de fijación más difundidos siguen siendo los aldehídos (formaldehído y glutaraldehído), siendo el formol el fijador más utilizado. (9-10)

El proceso de inclusión en parafina aumenta la tinción de fondo respecto a las secciones congeladas. Previamente a la aplicación de las técnicas es preciso una desparafinación lo más completa posible. (7, 11-12)

Los cortes en parafina se obtienen con un grosor que oscile entre 5 y 10 micrones (13). Se debe tener en cuenta que cortes demasiado finos facilitarán el desprendimiento de los tejidos en los múltiples lavados y disminuirá la concentración antigénica. Los cortes de mayor grosor originarán superposición celular, dificultades en la desparafinación y disminución en el número de muestras que es posible obtener de cada lesión.

Debido a los numerosos lavados que deben efectuarse, es frecuente que se desprendan los cortes, se recomienda usar un adhesivo que fije las secciones a los portaobjetos.

La pérdida de antigenicidad inducida por el uso de fijadores que contienen aldehídos pueden atenuarse mediante el uso de enzimas proteolíticas que desenmascaren los antígenos y aumente la inmunotinción. La digestión enzimática no es recomendable de modo universal, ya que, en algunos casos, puede aumentar la destrucción de los tejidos y antígenos, creando falsos negativos y aumentando la tinción inespecífica. Cuando es necesaria la digestión enzimática con agentes proteolíticos, disponemos de diferentes enzimas, se destacan la tripsina, proteasa, pronasa, solución de pepsina, etc. $(11,14-15)$

Posteriormente al tratamiento enzimático y antes de la aplicación de los anticuerpos, es necesario inhibir la actividad de la peroxidasa endógena mediante peróxido de hidrógeno, para evitar la tinción de fondo inespecífica. (16-17-18-19)

Los cambios de dilución del anticuerpo primario a utilizar van a determinar variaciones en los resultados.

Los cromógenos más difundidos son la 3-3-diaminobencidina (DAB) y el 3-amino-9-etilcarbazol $(A E C)$, que ofrecen un color marrón y rojo, respectivamente. Los inconvenientes del primero son que el color puede inducir confusión con pigmentos melánicos y hemáticos presentes en algunas lesiones (17). El segundo es soluble en disolventes orgánicos. El medio de contraste asociado habitualmente a los procedimientos inmunohistoquímicos es la hematoxilina de Mayer.

Para asegurar que el procedimiento técnico que estamos utilizando se desarrolla correctamente, es necesario hacer una serie de controles $(17,20-21$ 22). El control negativo consiste en reemplazar el anticuerpo primario por suero no inmune, otro anticuerpo o buffer, utilizando el mismo tejido que para el control positivo, si se obtiene positividad ésta será inespecífica. En el control positivo se utiliza una muestra de tejido que se procesa igual que el resto de las secciones, en la que se tiene la certeza de que se encuentra el antígeno objeto de estudio. Se añadirá esta muestra a cada batería, con el objeto de controlar la positividad. Si en la muestra de control obtenemos resultado negativo, significará que existe algún fallo en el procedimiento y que se ha obtenido un resultado falsamente negativo.

Causa de falsos negativos: Mala fijación, manejo defectuoso de los cortes, desnaturalización de los antígenos por el calor (que impide que los anticuerpos los reconozcan), enmascaramiento antigénico o densidad antigénica por debajo de los niveles de detección, uso de diluciones elevadas del anticuerpo, interpretación incorrecta.

Causas de falsos positivos: Presencia de peroxidasa endógena por una mala inhibición, reacciones cruzadas inespecíficas entre antígenos y anticuerpos, artefactos por dilución o por deficiente dilución del cromógeno, interpretación incorrecta de los resultados. 


\section{CONCLUSIONES}

Sólo el estudio histopatológico permite el diagnóstico de certeza, la sobreexpresión de la proteína p53 está relacionada con la prognosis, de allí que su marcación mediante técnicas inmunohistoquímicas contribuya al diagnóstico en anatomía patológica. En los 5 especímenes marcados, hubo positividad con el inmunosuero específico para dicha proteína.

Las técnicas de inmunohistoquímica además, permiten clarificar diagnósticos marcando diferentes proteínas como la p53 mencionada, las queratinas de alto y bajo peso molecular, la MIB-1, la p21 de connotaciones similares a la p53 y también los factores de crecimiento tumoral cuya importancia radica en que pueden modificar la función y estructura de los factores transcripcionales cuando interactúan con ellos.

Se aclara además, el valor de la inmunomarcación ante tumores sumamente indiferenciados o metastásicos a fin de posibilitar el hallazgo del primario.

\section{BIBLIOGRAFÍA}

1. Nakane PK, Pierce GB. Enzime-labelled antibodies: preparation and application for the localization antigen. J Histochem Cytochem. 1966; 14: $929-931$.

2. Graham RC, Karnovsky MJ. The early stages of absorption of injected horseradish peroxidase in the proximal tubules of mouse kidney: ultrastructural cytochemistry by a new technique. J Histochem Cytochem. 1966; 14: 291 - 302.

3. Taylor CR, Kledzik G. Inmunologic technique in surgical pathology: a spectrum of new special stains. Hum Pathol. 1981; 12: 590 - 596.

4. Doherty MJ, Russo GG, Jolly HW, Stewart KR. Inmunoenzime technique in dermatopathology. J Am Acad Dermatol. 1989; 20: 827 - 837.

5. Erausquin J. Apuntes de Técnica Histológica. $6^{\mathrm{a}}$ ed. El Ateneo. 1951.
6. Cavalcanti de Araujo V, Biazolla ER, Perri Moraes $N$, Furuse TA, and Melhado RM. Basaloid squamous cell carcinoma of the oral cavity. Sao Pablo, Brazil. Oral Surg Oral Med Oral Pathol. 1993; 75: 622 - 5.

7. DeLellis RA, Dayal Y. The role of inmunohistochemistry in the diagnosis of poorly differentiated malignant neoplasms. Semin Oncol. 1987; 14: 173 - 192.

8. Campo E, Quesada E, Palacín A. Detección inmunohistoquímica de marcadores tumorales. Técnicas y aplicaciones. Laboratorio. 1984; 78: $461-472$.

9. Pinkus GS. Diagnostic inmunocytochemistry of paraffinembedded tissues. Human Pathol. 1982; 13: 411 - 415 .

10. Taylor CR, Hofman FM, Modlin RL, Rea TH. Inmunoperoxidase technique applied to dermatopathology. J Ctan Pathol. 1983; 10: 145 - 163.

11. True LD. Atlas of diagnostic inmunopathology. ( $1^{\mathrm{a}}$ ed.) Filadelfia - Nueva York: JB Lippicott Co, Gower Medical Publishing. 1990.

12. Nadji M. Inmunoperoxidase technique. I: facts and artifacts. Am J Dermatopathol. 1986; 8: 32 36.

13. Cordón C, Serrano S, Corominas JM. Inmunopatías (II). Med Clin (Barc). 1985; 85: 28 $-31$.

14. Ordóñez NG, Manning JT, Brooks TE. Effect of trypsinization on the inmunostaining of formalinfixed, paraffin embedded tissues. Am J Surg Pathol. 1988; 12: 121 - 129.

15. Giddings J, Griffin R, Maciver AG. Demostration of inmunoproteins in Araldit-embedded tissues. J Clin Pathol. 1982; 35: 111 - 114.

16. DeLellis RA, Sternberger LA, Mann RB, Banks PM, Nakane PK. Inmunoperoxidase techniques in diagnostic pathology. Am J Clin Pathol. 1979; 71: 483 - 488 . 
17. López JA, Blanco J, Ortega L, Sanz J. Inmunohistoquímica en el diagnóstico oncológico. Oncología. 1991; 14: 270 - 278.

18. Falini B, Yaylor CR. New developments in inmunoperoxidase techniques and their application. Arch Pathol Lab Med. 1983; 107: 105 - 117.

19. Taylor CR. Inmunoperoxidase techniques. Practical and theorical aspects. Arch Pathol Lab Med. 1978; 102: 113 - 121.

20. Gómez M, Rodríguez MD, Sáenz F. Técnicas inmunohistoquímicas. (II). En: Gracía del Moral $\mathrm{R}$, editor. Laboratorio de anatomía patológica. Madrid: McGraw-Hill. 1993; 341 - 368.

21. Matthews JB. Inmunocytochemical methods: a technical overview. J Oral Pathol. 1987; 16: 189 - 195.
22. Elías JM, Grown AM, Nakamura RM et al. Special report: quality control in inmunohistochemistry. Report of workshop sponsored by the Biological Stain Comission. Am J Clin Pathol. 1989; 92: $836-843$.

\section{CORRESPONDENCIA}

Dra. Baudo JE.

Calle $11, \mathrm{n}^{\circ} 28$ e/ 531 y 532 Tolosa (1900)

La Plata. Bs. As. Argentina.

Tel.: 0054-221-4834289

drabaudo@yahoo.com.ar 